\title{
Role of the neodymium YAG laser in the managemen of tracheal tumours
}

\author{
P J M GEORGE, C P O GARRETT, M R HETZEL \\ From the National Medical Laser Centre, University College Hospital, London
}

ABSTRACT Twenty one patients with tracheal tumours (10 primary and 11 secondary) have bee芯 treated with the neodymium YAG laser under general anaesthesia. Fourteen of these patient\$ presented with impending asphyxia and in 11 cases this was dramatically relieved with emergenc laser treatment. The improvements in peak expiratory flow (PEF) ranged from $26 \%$ to $512 \%$. The three patients who did not respond were immediately given other treatments but died in hospital. The remaining seven patients were not in severe respiratory distress and were treated electively; af were thought to have benefited from their treatment, the mean increase in PEF being $36 \%$. Thळ improvement obtained in the 11 patients who responded to emergency laser treatment provide time in which to assess the disease carefully and plan the most appropriate longer term managemen: with surgery, radiotherapy, tracheal stenting, or repeat laser treatment. The patients who were treated electively have either not required further treatment or have been managed with repeat lasę treatments alone. Laser treatment provides an excellent method of resuscitating patients with lif: threatening tracheal obstruction and enables subsequent management to be carefully planned. I8 some cases this longer term management should be with further laser treatment alone.

Tumours of the trachea are notoriously difficult to manage. Often the correct diagnosis is not made until a relatively late stage in the disease, when there is advanced obstruction of the airway. ${ }^{12}$ Conventional treatment with emergency surgery or radiotherapy may be effective but may carry an appreciable risk in patients who are close to asphyxiation. Patients who have already undergone conventional treatment may relapse with locally recurrent disease. ${ }^{34}$ Most will be unsuitable for further radiotherapy, yet they are liable to suffer considerable distress from breathlessness and they may die by gradual asphyxiation.

It has recently become possible to treat these two groups of patients by endoscopic laser resection and encouraging results have been reported. ${ }^{5-7}$ We present the results of treating a series of patients with the neodymium YAG laser and consider the place of this treatment in relation to more conventional methods.

Address for correspondence: Dr PJM George, University College Hospital, London WC1E 6AU (no reprints available).

Accepted I December 1986

\section{Patients and methods}

PATIENTS

From February 1984 to February 1986, 21 patient with tracheal tumours were referred to us for lasef treatment. Tissue for histological examination was obtained from all patients and the tumour types are shown in table 1 . For the 10 patients (seven of theng men) with primary tumours the average age was 63 years. Details of the patient with a primary malignang mixed tumour have already been reported. ${ }^{7}$

For the 11 patients (five of them men) with second을 ary tumours the average age was 65 years. The site of the primary tumour was the lung in eight patients, the

Table 1 Numbers of patients with different histological types of tracheal tumours (numbers requiring emergency treatment in parentheses)

\begin{tabular}{|c|c|c|}
\hline Histology & Primary & Secondary \\
\hline $\begin{array}{l}\text { Squamous cell } \\
\text { Adenocarcinoma }\end{array}$ & $i_{1}^{6(3)}$ & $i_{1}^{6(6)}$ \\
\hline Small cell & - & i (1) \\
\hline Adenoid cystic & 2 & - \\
\hline Malignant mixed & $\underline{1}(1)$ & $\overline{2}(2)$ \\
\hline $\begin{array}{l}\text { Thyroid } \\
\text { Clear cell }\end{array}$ & 二 & 1 (1) \\
\hline Total & $\overline{10}(4)$ & $11(10)$ \\
\hline
\end{tabular}


thyroid (carcinoma) in two patients, and the kidney (clear cell adenocarcinoma) in one patient.

\section{Indications for laser treatment}

On referral, 14 patients were in severe respiratory distress and were treated urgently with the laser; three of these patients had suffered episodes of apnoea before referral. The remaining seven were not severely breathless and were treated electively on the next routine list.

\section{Previous management}

Fourteen patients requiring emergency laser treatment Eight patients had not received any previous treatment; misdiagnosis (six patients) and delayed presentation (two patients) were thought to have contributed to the advanced state of their tracheal obstruction. The remaining six had all undergone treatment with radiotherapy; four had radioresistant tumours and their breathlessness was caused by gradual tumour progression, while two had suffered apnoeic episodes soon after starting radiotherapy as a result of presumed radiation induced oedema.

Seven patients treated electively Two patients with primary tumours had not received any previous treatment; they had been diagnosed before developing severe breathlessness and were referred for laser treatment when staging had shown that the tumours were inoperable. The remaining five patients had relapsed after previous treatment with either surgery and radiotherapy (one patient) or radiotherapy alone (four patients); all were considered unsuitable for further radiotherapy.

\section{LASER TREATMENT}

All patients were treated with a neodymium YAG laser (Fiberlase 100, Pilkington Medical Systems). General anaesthesia was induced with etomidate and then maintained with intravenous infusions of etomidate and alfentanil. The patient was paralysed with atracurium, intubated with a Storz ventilating bronchoscope, and jet ventilated with a Sanders injector. The fibreoptic bronchoscope was then passed inside the rigid bronchoscope and was used to aim the laser beam. More complete details of this method have already been published. ${ }^{8}$ One patient who had previously undergone a tracheostomy and laryngectomy for a laryngeal carcinoma could not be intubated with the rigid bronchoscope. He was anaesthetised with etomidate and alfentanil and was allowed to breathe spontaneously. The fibreoptic bronchoscope was then passed through the tracheostomy site and was used to direct the laser beam at the tumour.

Laser treatment was continued until all intra- luminal tumour had been removed from the airway. The final diameter of the trachea was therefore determined by the degree of extrinsic compression caused by untreatable extraluminal tumour.

\section{Results}

\section{BENEFITS OF LASER TREATMENT}

Patients requiring emergency laser treatment

Eleven of the 14 patients derived immediate and dramatic clinical benefit. By three days after treatment peak expiratory flow (PEF) was $26-512 \%$ higher than immediately before treatment (fig 1 ). The patient with a tracheostomy could not provide a PEF measurement but felt considerably improved by treatment. Three patients who were not improved clinically did not show increases in PEF (fig 1).

Case history A 61 year old man was found to have a primary squamous cell carcinoma of the lower trachea. The tumour overlay the main carina, so that it had almost completely obstructed the orifice of the right main bronchus and partially obstructed that of the left. As he had already experienced several episodes of near asphyxia, he was treated urgently with the laser. This restored full patency to the orifice of the left main bronchus and reasonable patency to that of the right. His breathlessness was dramatically relieved and flow-volume loops showed considerable improvements in inspiratory and expiratory flow, in addition to an increase in vital capacity (fig $2 a$ ). He was subsequently treated with radiotherapy and has since remained well for nine months.

\section{Patients treated electively}

All seven patients were thought to have benefited from their treatment. In six patients PEF increased by $18-117 \%$ (fig 1). One patient showed no increase in PEF; the trachea, however, was not critically nar-
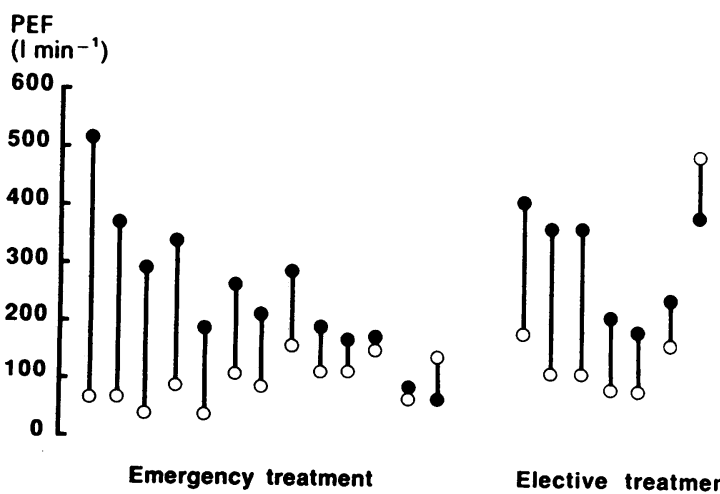

Fig 1 Peak expiratory flow (PEF) measured immediately before $(\bigcirc)$ and three days after (O) emergency or elective laser treatment. 
Flow rate

$\left(1 \mathrm{~s}^{-1}\right)$

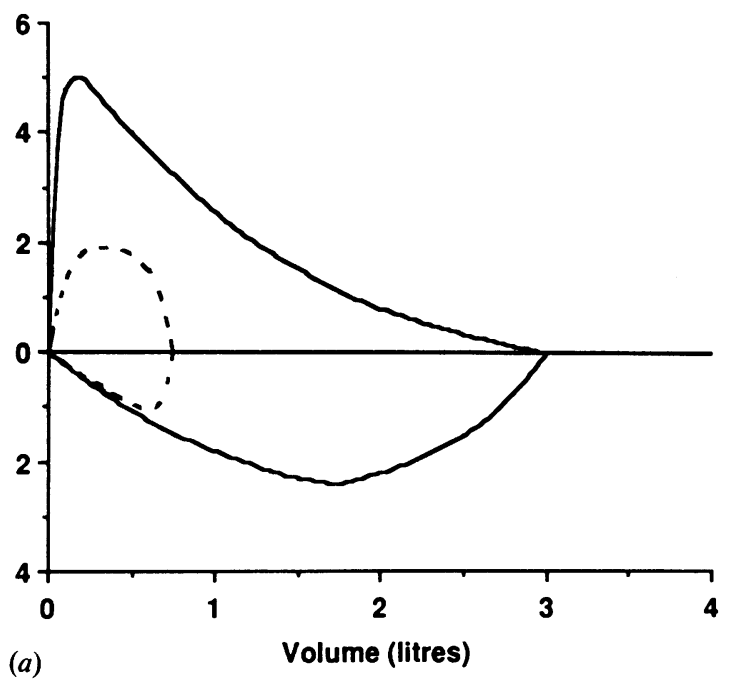

Flow rate

$\left(\mid \mathrm{s}^{-1}\right)$

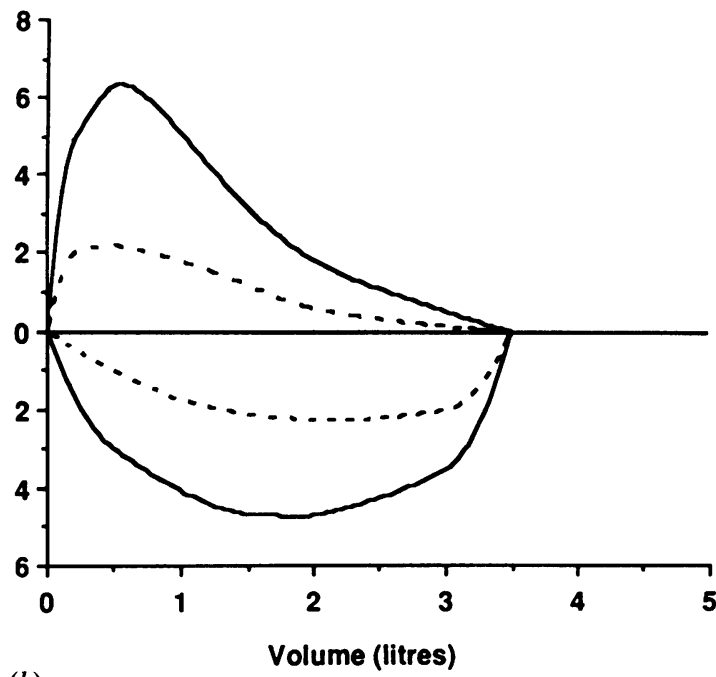

(b)

Fig 2 Flow-volume loops (expiratory upper, inspiratory lower) before (dotted line) and three days after (continuous line) laser treatment in two patients with primary tracheal tumours. Details of each patient are given in the case history sections; figure $2 a$ applies to case $I$ and figure $2 b$ to case 2 .

rowed. This patient had already received radiotherapy without reduction in size of the intraluminal tumour. Laser treatment was given to delay the onset of more severe breathlessness and, as the patient remains in good health $\mathbf{2 0}$ months later, it is likely to have been successful in this.
Case history A 61 year old man gave a five year history of hoarseness of his voice, a feeling of fullness in the throat, and increasing breathlessness on exertion. Bronchoscopy showed an adenoid cystic carcinoma extending from immediately below the vocal cords to $\frac{\bar{\omega}}{\partial}$ the lower third of the trachea. The lesion was consid- $\mathbb{D}$ ered to be inoperable and so he was referred for lasero treatment. In one treatment the patency of the tra- cheal lumen was increased from about $40 \%$ to $80 \%$ of normal. This produced an immediate symptomatic $\vec{\omega}$ improvement and flow-volume loops showed an appeciable improvement in inspiratory and $\overrightarrow{\vec{x}}$ expiratory flow rates $($ fig $2 b$ ). He has since required $\stackrel{N}{N}$ two further treatments at intervals of three and fouros months.

\section{COMPLICATIONS OF LASER TREATMENT}

One serious complication was seen in a patient with a secondary tumour. This patient became acutely气 breathless three hours after laser treatment as a result $\overrightarrow{\mathrm{D}}$ of oedema and fibrinous exudate at the site of treat- $\vec{v}$ ment. This was successfully managed by emergency@ bronchoscopic debridement and further laser resection. Bleeding occurred in all patients during treatment but was easily controlled and did not seriously compromise the airway.

\section{SUBSEQUENT MANAGEMENT}

\section{Patients requiring emergency laser treatment}

The improvement that was gained in 11 patients pro- $\exists$ vided time in which to assess the disease carefully and plan the most appropriate longer term management. One patient with a primary malignant mixed tumour underwent staging and then had a successfully elective tracheal resection. ${ }^{7}$ The two patients who $x$ suffered apnoeic episodes as a result of radiation 3 induced oedema were both able to continue theiro courses of radiotherapy in safety, while three other 3 patients received radiotherapy without incident. Two patients have been managed by radiotherapy and? repeat laser treatment and one has been managed byo a combination of repeat laser treatment, radiotherapy, and tracheal stenting. Two patients who hader already received maximum permissible doses of radiotherapy have been successfully managed byN repeat laser treatment alone. All 11 patients were welf enough to be discharged from hospital and have lived independently at home.

The three patients who were not improved with the laser were immediately given other treatment. One patient received a tracheal stent; although this relieved her breathlessness, she died three days later $\mathbb{\mathbb { D }}$ It was assumed that she had died from a cardiac dys $\frac{\text { }}{\mathrm{D}}$ rhythmia, no other cause having been established af postmortem examination. The remaining two were given radiotherapy but did not improve appreciably 
and died in hospital three and four weeks after the initial laser treatment, one patient dying from asphyxia and the other from pneumonia.

\section{Patients receiving elective laser treatment}

Four of seven patients have not required any further treatment and three have been satisfactorily managed with repeat laser treatments alone. All have been able to live independently at home.

SUR VIVAL

The period of survival has been measured from the time of the first laser treatment. Eight patients with

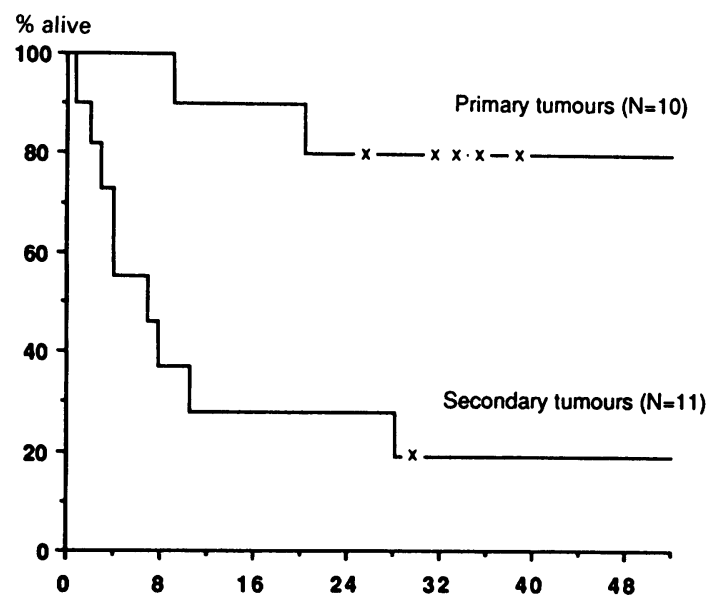

(a)

Estimated survival in weeks

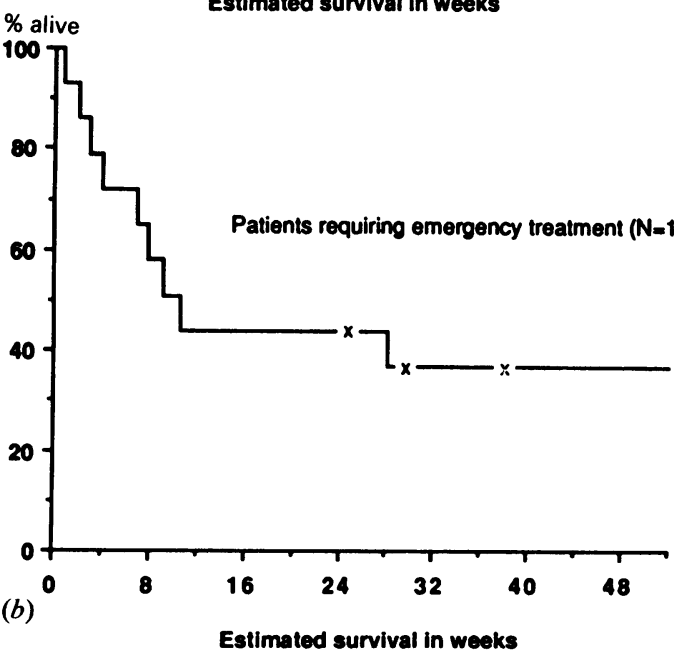

Fig 3 Life tables of estimated survival (at weekly intervals from the time of initial laser treatment) $(a)$ in 21 patients with either primary or secondary tracheal tumours and $(b)$ in the subgroup of 14 patients who required emergency treatment. $\times$ denotes periods of follow up of less than one year in individual patients. primary tumours remain alive six to 21 months after initial laser treatment and two have died after two and five months. Two patients with secondary tumours remain alive seven and 15 months after initial treatment and nine have died after a mean survival of 52 days. As the period of follow up is relatively short in some patients, the log rank test ${ }^{9}$ has been used to prepare life tables of estimated survival over a one year period for the primary and secondary tumour groups and also for the patients who required emergency laser treatment (fig 3). After nine weeks the differences in survival between the primary and secondary tumour groups were found to be highly significant $(\mathrm{p}<0.001)$.

The immediate causes of death are given in table 2 . Of the 11 patients who died, only two became asphyxiated; in one case this was after failing to respond to both laser treatment and radiotherapy, and in the other case after a short period of symptomatic relief following laser treatment. The cause of death was not known in one patient, who died unexpectedly while at home.

\section{Discussion}

Tumours of the trachea are relatively rare and are frequently mistaken for more common conditions such as asthma. ${ }^{10-12}$ In this series six patients were originally misdiagnosed and the consequent delay contributed to the severity of their respiratory distress. Endoscopic laser resection provides an excellent method of relieving asphyxia in these patients. The method of treatment appears to be safe and, in most cases, produces a response that is immediate and dramatic. The improvement that is gained provides time in which to assess the disease carefully and then decide on the most appropriate longer term management.

These newly diagnosed patients could have been managed more conventionally by emergency surgery or radiotherapy; the chances of a successful outcome, however, would probably have been much reduced. In the patient who later underwent elective surgery emergency laser treatment had the advantage of pro-

Table 2 Immediate causes of death in 11 patients

\begin{tabular}{|c|c|c|}
\hline \multirow[b]{2}{*}{ Mode of death } & \multicolumn{2}{|c|}{ Number dying } \\
\hline & At home & In hospital \\
\hline $\begin{array}{l}\text { Asphyxia } \\
\text { Cachexia } \\
\text { Pneumonia } \\
\text { Haemoptysis } \\
\text { Cardiac dysrhythmia } \\
\text { Unknown } \\
\text { Total }\end{array}$ & $\frac{\frac{2}{1}}{\frac{1}{1}}$ & $\begin{array}{l}2 \\
2 \\
\frac{2}{1} \\
\frac{1}{7}\end{array}$ \\
\hline
\end{tabular}


viding time in which to treat his chest infection, withdraw steroid treatment, and then stage the disease. ${ }^{7}$ In the patients who were given radiotherapy laser treatment helped to protect the airway from the effects of radiation induced oedema. Thus the two patients who developed apnoeic episodes after starting radiotherapy were both able to complete their courses without further discomfort from dyspnoea.

Although radiotherapy may produce a prolonged remission, many patients will relapse with locally recurrent disease. ${ }^{34}$ Most of these patients will be unsuitable for further radiotherapy and so laser treatment is an attractive option. In the present series seven patients were successfully managed by laser treatment alone after receiving maximum permissible doses of radiotherapy. We conclude that the laser led to a considerable improvement in the quality of life in these patients and helped to avoid a distressing death by asphyxiation.

The three patients who did not respond to laser treatment all had extensive extraluminal tumour causing appreciable extrinsic compression of the airway. One patient had already received maximum permissible doses of radiotherapy and was improved by a tracheal stent. ${ }^{13}$ The other two patients were given radiotherapy but did not improve; possibly they would also have benefited from a stent. This treatment may also be valuable in patients with rapidly growing tumours. One patient in our series responded to repeated laser treatments and radiotherapy, but relapsed after progressively shorter intervals as the tumour began to grow more quickly. When the benefits of laser treatment were outweighed by the inconvenience of multiple hospital admissions, he agreed to a tracheal stent and this has enabled him to enjoy a reasonably active life at home.

Of the nine patients who have been managed exclusively with the laser from the time of their referral, four have undergone repeat treatments at intervals ranging from 19 to 126 days, while five have not required further treatment after periods of follow up ranging from five to 20 months. In some patients therefore laser treatment alone produces reasonably durable palliation.

Although the period of survival in some of these patients was relatively brief (fig 3 ), we believe that treatment was worthwhile. Most of the patients who were admitted to hospital in severe respiratory distress were dramatically improved and some were able to remain at home until the time of their death (table 2 ); in most cases death from asphyxia was avoided. Failure to have attempted palliation in these apparently desperate cases would have denied many patients a good quality life for a considerable period of time, while one patient would have been denied the chance of a cure. ${ }^{7}$
As this series lacks a control group, we cannot determine precisely the contribution of laser treat- $\stackrel{D}{\rightarrow}$ ment to survival. In the light of such dramatic responses, however, in patients with critical trachealo narrowing (see, for example, fig $2 a$ ), it has been sug- $\frac{\bar{p}}{\bar{P}}$ gested that it would be unethical to perform a trial $\Phi^{\Phi}$ with a control group in which laser treatment was withheld. ${ }^{14}$

This work was generously supported by Pilkington $\overrightarrow{\vec{\omega}}$ Medical Systems and the North East Thames Regional Health Authority. We are also indebted to $\vec{x}$ Dr TN Mills and Sister A Ramu for their continuing technical support and to Dr MR Lewin for statistical advice.

\section{References}

1 Houston HE, Harrison EG, Olsen AM. Primary cancers ${ }^{\circledR}$ of the trachea. Arch Surg 1969;99:132-40.

2 Hajdu SI, Huvos AG, Goodner JT, Foote FW, Beattie JR. Carcinoma of the trachea: clinicopathologic study of 41 cases. Cancer 1970;25:1448-56.

3 Rostom AY, Morgan RL. Results of treating primary tumours of the trachea by irradition. Thoraxo 1978;33:387-93.

4 Baraka ME. Malignant tumours of the trachea. Ann $R_{\Omega}^{\stackrel{\complement}{\Phi}}$ Coll Surg Engl 1984;66:27-9.

5 Laforet EG, Berger RL, Vaughan CW. Carcinoma응 obstructing the trachea: treatment by laser resection. N Engl J Med 1976;294:941.

6 Toty L, Personne C, Colchen A, Vourc'h G. Bronchoscopic management of tracheal lesions using the neodymium yttrium aluminium garnet laser. Thorax 1981;36:175-8.

7 George PJM, Garrett CPO, Goldstraw P, Hetzel MR,윽 Ramsay AD. Resuscitative laser photoresection of $\mathrm{a}$ tracheal tumour before elective surgery. Thoraxô 1986;41:812-3.

8 Hetzel MR, Nixon C, Edmonstone WM, et al. Lasero therapy in 100 tracheobronchial tumours. Thorax 1985;40:341-5.

9 Peto R, Pike MC, Armitage P, et al. Design and analysis of randomized clinical trials requiring prolonged observation of each patient. II: Analysis and examples. Br J Cancer 1977;35:1-39.

10 Harrison BDW. Upper airways obstruction-a report on 16 patients. $Q J$ Med 1976;45(180):625-45.

11 Isaacs D, Smyth JT, Bradbeer TL, Pagliero KM. Intra thoracic tracheal tumour presenting as asthma. $B r$ Med J 1977;ii:1332.

12 Parrish RW, Banks J, Fennerty AG. Tracheal obstruction presenting as asthma. Postgrad Med J1983;59:775-6.

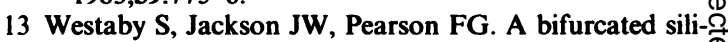
cone rubber stent for relief of tracheobronchial $\stackrel{\circ}{\circ}$ obstruction. J Thorac Cardiovasc Surg 1982;83:414-7.O

14 Beamis JF, Shapsay SM. More about the YAG. Chest 1985;87:277-8. 


\section{Corrections}

\section{Predictive value of sputum cytology}

The paper by Dr J Benbassat and others (March 1987;42:165-72) contained miscalculations in two areas. The first relates to the calculated age and sex specific annual incidence rates (per 100000 population) of cancer of the lung and bronchi by smoking habit in table 3 . This should read as in the table below.

The second error relates to the calculation of the prevalence of presymptomatic squamous cell lung cancer in the population. In calculating it the authors did not consider the fact that almost all occult cancers are squamous eell cancer, which comprises only $40-60 \%$ of all histological types of lung cancers. Thus the correct calculation of the pretest probability of squamous cell lung cancer in a 60 year old non-smoking woman would be $10 \cdot 2$ (incidence of lung cancer in general per 100000 non-smoking women aged 60-64) divided by 2 (to obtain the incidence of squamous cell cancer) and multiplied by $\mathbf{4 . 4 8}$ years (the estimated duration of detectable preclinical disease from exfoliation of cells with marked atypia to detection of lung cancer), which equals $22 \cdot 8 / 100000$. The corrected likelihood that a non-smoking 60 year old woman with positive sputum cytology actually has lung cancer is therefore $24.9 \%$ and not $20.1 \%$ as erroneously calculated in the paper.

The authors point out that these corrections do not invalidate their conclusion that exfoliative sputum cytology is not a definitive diagnostic test for lung cancer.

Age and sex specific annual incidence rates (per 100000 population) of cancer of the lung and bronchi by smoking habit*

\begin{tabular}{|c|c|c|c|c|c|c|}
\hline \multirow{3}{*}{$\begin{array}{l}\text { Age } \\
(y)\end{array}$} & \multicolumn{6}{|c|}{ Annual incidence per 100000 population } \\
\hline & \multicolumn{3}{|l|}{ Men } & \multicolumn{3}{|c|}{ Women } \\
\hline & All & Non-smokers & Smokers & All & Non-smokers & Smokers \\
\hline $\begin{array}{l}50-54 \\
55-59 \\
60-64 \\
65-69 \\
70-74 \\
75+\end{array}$ & $\begin{array}{r}48.1 \\
84.9 \\
110.2 \\
176.9 \\
247.6 \\
283.1\end{array}$ & $\begin{array}{l}10 \cdot 6 \\
18.6 \\
24 \cdot 2 \\
38.8 \\
54.4 \\
62.2\end{array}$ & $\begin{array}{l}105.6 \\
186.4 \\
241.9 \\
388.4 \\
543.6 \\
621.5\end{array}$ & $\begin{array}{l}16 \cdot 6 \\
33 \cdot 3 \\
31 \cdot 8 \\
50 \cdot 2 \\
60 \cdot 9 \\
80 \cdot 5\end{array}$ & $\begin{array}{r}5 \cdot 3 \\
10 \cdot 6 \\
10 \cdot 2 \\
16 \cdot 0 \\
19 \cdot 4 \\
25 \cdot 7\end{array}$ & $\begin{array}{r}53.0 \\
106.3 \\
101.5 \\
160.2 \\
194.4 \\
256.9\end{array}$ \\
\hline
\end{tabular}

*These figures apply to Israel and they are based on the assumptions that $(a)$ the relative risk for lung cancer in all smokers is $10 \cdot 0$, and $(b)$ the incidence of smoking in all age groups is $39.5 \%$ for men and $23.7 \%$ for women.

\section{Rapid diagnosis of sputum negative miliary tuberculosis using the fexible fibreoptic bronchoscope}

In the letter by Dr WS Kwee (May 1987;42:399-400) the first sentence on page 400 should read "Twenty one cases were diagnosed by this combination of $Z N$ (12 positive cases) and AR (19 positive cases) staining techniques...."
Role of the neodymium YAG laser in the management of tracheal tumours

Reprints of the paper by Dr PJM George and others (June $1987 ; 42: 440-4)$ are available; we regret it is stated that they are not.

\section{Notices}

\section{Epidemiology and medical statistics course}

An intensive course in epidemiology and medical statistics will be held at the Cardiothoracic Institute, Brompton Hospital, from 26 to 30 October 1987 (course fee £20). Inquiries to postgraduate course secretary, Cardiothoracic Institute, Fulham Road, London SW3 6HP (01 3528121 ext 8003).

\section{Symposium on cardiorespiratory emergencies}

The Fourth International Symposium on Cardiorespiratory Emergencies will be held from 16 to 20 November 1987 at the Doelen Concert Hall, Rotterdam, The Netherlands. Tutorials, exhibits, and posters as well as scientific papers will be included. Further information from Dr Omar Prakash, Erasmus University, PO Box 1738, 3000 DR Rotterdam, The Netherlands (tel 010-4635212; telex 25267). 